Article

\title{
Underestimated Peripheral Effects Following Pharmacological and Conditional Genetic Microglial Depletion
}

\author{
Jinming Han ${ }^{1, *} \mathbb{B}$, Yueshan Fan ${ }^{1}$, Kai Zhou ${ }^{2}$, Keying Zhu ${ }^{1}\left(\mathbb{D}\right.$, Klas Blomgren $^{2,3}{ }^{\mathbb{D}}$, \\ Harald Lund ${ }^{1,4}{ }^{(}$, Xing-Mei Zhang ${ }^{1}$ and Robert A. Harris ${ }^{1, *(\mathbb{C})}$ \\ 1 Applied Immunology and Immunotherapy, Department of Clinical Neuroscience, Karolinska Institutet, \\ Center for Molecular Medicine, Karolinska University Hospital, S-171 76 Stockholm, Sweden; \\ fanyueshan@hotmail.com (Y.F.); keying.zhu@ki.se (K.Z.); harald.lund@ki.se (H.L.); \\ xingmei.zhang@ki.se (X.-M.Z.) \\ 2 Department of Women's and Children's Health, Karolinska Institutet, Karolinska University Hospital, \\ S-171 76 Stockholm, Sweden; kai.zhou@ki.se (K.Z.); klas.blomgren@ki.se (K.B.) \\ 3 Pediatric Oncology, Karolinska University Hospital, S-171 76 Stockholm, Sweden \\ 4 Department of Physiology and Pharmacology, Karolinska Institutet, Center for Molecular Medicine, \\ Karolinska University Hospital, S-171 76 Stockholm, Sweden \\ * Correspondence: jinming.han@ki.se (J.H.); robert.harris@ki.se (R.A.H.); Tel.: +46-(0)700143902 (J.H.); \\ +46-(0)700021803 (R.A.H.)
}

Received: 21 October 2020; Accepted: 10 November 2020; Published: 15 November 2020

\begin{abstract}
Microglia, predominant parenchymal resident macrophages in the central nervous system (CNS), are crucial players in neurodevelopment and CNS homeostasis. In disease conditions, pro-inflammatory microglia predominate over their regulatory counterparts, and are thus a potential immunotherapeutic target. It has been well documented that microglia can be effectively depleted using both conditional genetic $\mathrm{C} x 3 \mathrm{cr} 1^{\mathrm{Cre}}$-diphtheria toxin receptor (DTR)/diphtheria toxin subunit A (DTA) animal models and pharmacological colony-stimulating factor 1 receptor (CSF1R) inhibitors. Recent advances using these approaches have expanded our knowledge of the multitude of tasks conducted by microglia in both homeostasis and diseases. Importantly, experimental microglial depletion has been proven to exert neuroprotective effects in an increasing number of disease models, mostly explained by reduced neuroinflammation. However, the comprehensive effects of additional targets such as circulating monocytes and peripheral tissue macrophages during microglial depletion periods have not been investigated widely, and for those studies addressing the issue the conclusions are mixed. In this study, we demonstrate that experimental microglial depletion using both $C \times 3 c r 1^{\mathrm{CreER} /+} \operatorname{Ros} a 26^{\mathrm{DTA} /+}$ mice and different doses of CSF1R inhibitor PLX3397 exert crucial influences on circulating monocytes and peripheral tissue macrophages. Our results suggest that effects on peripheral immunity should be considered both in interpretation of microglial depletion studies, and especially in the potential translation of microglial depletion and replacement therapies.
\end{abstract}

Keywords: monocytes; tissue macrophages; colony-stimulating factor 1 receptor inhibitor

\section{Introduction}

Microglia are resident macrophages in the central nervous system (CNS), acting as key players in immune surveillance, neural circuits and synapse formation [1]. Growing evidence points toward a critical role of reactive microglia in disease conditions through their production of inflammatory mediators [2]. Conditional genetic and pharmacological tools have been widely used in order to ablate 
microglia in research settings, as we have previously reviewed [3-5]. These studies have expanded our understanding of microglial biology in both homeostasis and diseases.

Microglia are characterized by high expression of the chemokine receptor CX3CR1. Cx3cr1 is widely used to genetically label microglia and the Cre/loxP system is an applied technology for site-specific genetic manipulation in preclinical animal models [6]. Specifically, $C \times 3 c r 1^{\mathrm{Cre}}$-diphtheria toxin receptor (DTR) mouse, with a tamoxifen-inducible Cre-recombinase expressed under control of the $C x 3 c r 1$ promoter, was bred in order to deplete microglia after the activation of tamoxifen and intraperitoneal administration of diphtheria toxin [7]. This conditional genetic approach can deplete approximately $80 \%$ of microglia in the mouse brain [7]. In addition, treatment of $\mathrm{C} x 3 \mathrm{cr} \mathrm{C}^{\mathrm{CreER} /+} \mathrm{C} \mathrm{S} f 1 r^{\text {Flox/Flox }}$ mice with a 12-week tamoxifen diet resulted in partial depletion of microglia [8]. We have previously reported that microglia are efficiently eliminated by administration

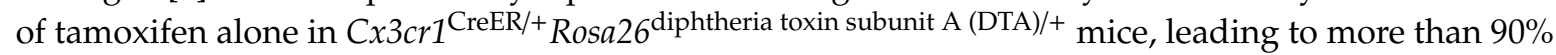
depletion of microglia $[9,10]$. However, it is important to note that other peripheral immune cells including activated T cells and NK cells also express CX3CR1 [11].

The survival, maintenance and proliferation of microglia are profoundly dependent on the colony-stimulating factor 1 receptor (CSF1R). CSF1R is a receptor tyrosine kinase which is mainly expressed on microglia within the CNS. The pharmacological targeting of CSF1R using compounds including PLX3397 [12], PLX5622 [13], BLZ945 [14], Ki20227 [15] and GW2850 [16] has been widely used in order to ablate microglia in both preclinical and clinical settings [17]. CSF1R inhibitors at different doses $(290 \mathrm{mg} / \mathrm{kg}$ or $1200 \mathrm{mg} / \mathrm{kg})$ can be added into diets and continuous dietary administration of these compounds to mice leads to effective microglial depletion [18]. Specifically, PLX3397 at a dose of $290 \mathrm{mg} / \mathrm{kg}$ for 14 consecutive days can deplete more than $80 \%$ of microglia in the spinal cord [18]. PLX5622, a more specific CSF1R inhibitor that does not inhibit c-Kit, at a dose of $1200 \mathrm{mg} / \mathrm{kg}$ for 7 days can eliminate over $85 \%$ of microglia in the brain [19]. Again, systematic administration of these CSF1R inhibitors may exert potential effects on peripheral immune cells and cause side-effects. In support of this notion, CSF1R-related leukoencephalopathy, a disease mainly caused by CSF1R gene mutations, can lead to a marked decreased frequency of circulating non-classical monocytes during disease progression [20].

Previous studies using currently available depletion approaches have mainly assessed effects on microglia in the CNS, and a few studies have reported that CSF1R inhibitors did not significantly alter leukocyte populations in the circulation [18,21]. For example, it has been recorded that PLX3397 at a concentration of $290 \mathrm{mg} / \mathrm{kg}$ does not affect the numbers and proportions of macrophages and T cells in both the spleen and draining lymph nodes [22]. These results implicate that CSF1R inhibitors specifically target microglia in the CNS, and reference to influences on peripheral immunity (without detailed testing) have been made [23]. However, emerging data has inferred the opposite conclusion that the gene expression csf1r of liver tissue macrophages can be reduced using both Cx3cr1-DTR rats and PLX5622 treatment [24]. PLX5622 diet at a concentration of $1200 \mathrm{mg} / \mathrm{kg}$ for 21 days, frequently used in research settings, could reduce the numbers of macrophages and monocytes in the periphery [25]. Furthermore, treatment of $C x 3 c r 1^{\mathrm{CreER} /{ }^{+}} C s f 1 r^{\text {Flox/Flox }}$ mice with tamoxifen caused an obvious deficiency of intestinal macrophages [8]. It has also been recently proposed that PLX5622 is not microglia specific and can also exert significant influences on peritoneum, lung, and liver tissue macrophages, with the splenic populations being less affected [26]. PLX5622 treatment also exerts long-term effects on hematopoietic progenitor cells and hematopoietic stem cells, affecting hematopoiesis [26].

Given this controversy in the research field, the objective of the present study was to confirm if experimental elimination of microglia using additional methods such as conditional genetic C $x 3$ cr $1^{\mathrm{CreER} /+}$ Rosa $26^{\mathrm{DTA} /+}$ mice and CSF1R inhibition (PLX3397) exerts effects on peripheral immunity with a focus on the spleen. 


\section{Results}

\subsection{Microglia Are Effectively Depleted 21 Days after PLX3397 Treatment}

We have previously reported that $\mathrm{CD} 11 b^{+} \mathrm{CD} 45^{\text {low }} \mathrm{Ly}_{6 \mathrm{C}^{-}} \mathrm{Ly}_{6 \mathrm{G}^{-}}$microglia can be effectively depleted (95\%) 7 days after the administration of tamoxifen in $C x 3 c r 1^{\text {CreER/+ }}{ }^{\text {Rosa26 }}{ }^{\mathrm{DTA} /+}$ mice $[9,10]$. In the current study, PLX3397 standard diet $(290 \mathrm{mg} / \mathrm{kg})$ was administered for up to 21 consecutive days in $C 57 B L / 6 N T a c$ mice, with control mice receiving a normal diet. Mice were terminated 18 or 21 days following PLX3397 treatment. No obvious side-effects were observed with PLX3397, except for whitening of fur color as previously reported [21]. Flow cytometric analyses of brain tissues were performed at each time point. Our results demonstrated that $\mathrm{CD} 11 \mathrm{~b}^{+} \mathrm{CD} 45^{\text {low }} \mathrm{Ly}_{6 \mathrm{C}^{-}} \mathrm{Ly}_{6 \mathrm{G}}^{-}$microglia can be effectively depleted 18 days $(79.82 \% \pm 4.45 \%)$ and 21 days $(95.81 \% \pm 1.91 \%)$ following PLX3397 treatment at a concentration of $290 \mathrm{mg} / \mathrm{kg}$ (Figure $1 \mathrm{~A}-\mathrm{C},{ }^{* * *} p<0.0001$ ).

\section{A PLX3397 treatment (brain)}

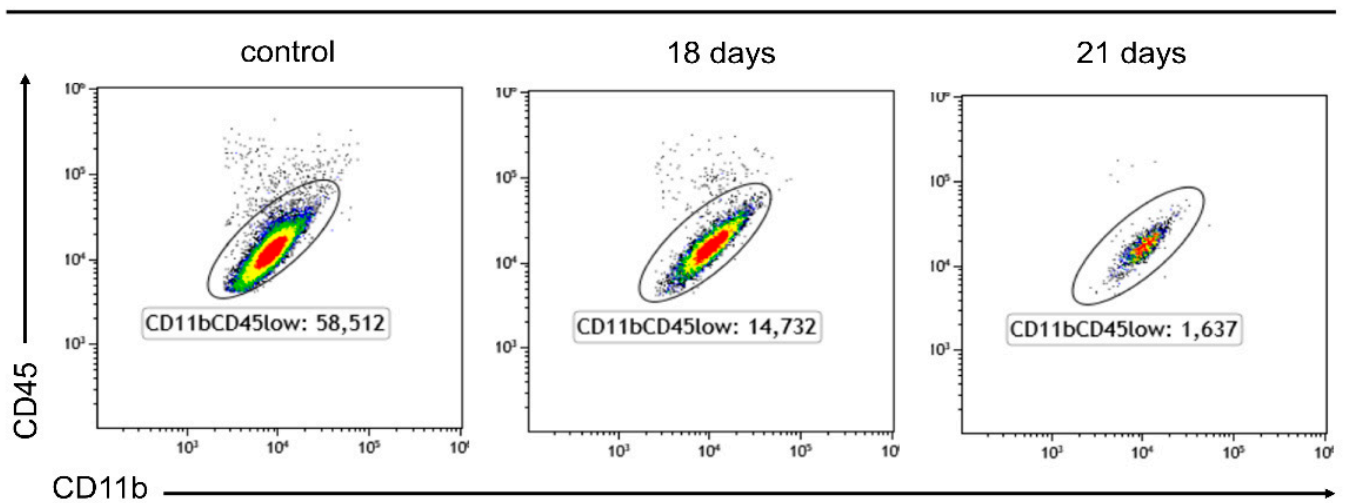

B

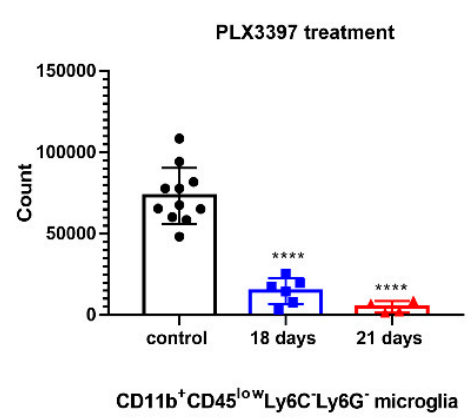

C

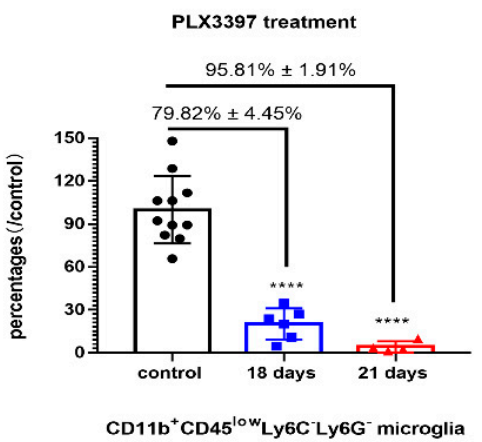

Figure 1. Microglia are effectively depleted 21 days following PLX3397 treatment. (A) Representative flow cytometry plots of $\mathrm{CD} 11 \mathrm{~b}^{+} \mathrm{CD} 45^{\text {low }} \mathrm{Ly} 6 \mathrm{C}^{-} \mathrm{Ly}_{6 \mathrm{G}}{ }^{-}$microglia of the hemi-brains in C57BL/6NTac mice following consecutive PLX3397 diet (18 and 21 days) at a dose of $290 \mathrm{mg} / \mathrm{kg}$. Control mice were treated with normal diet. (B) Total CD11b ${ }^{+} \mathrm{CD} 45^{\text {low }} \mathrm{Ly}_{6 \mathrm{C}^{-}} \mathrm{Ly}_{6 \mathrm{G}}{ }^{-}$microglial counts $( \pm \mathrm{SEM})$ of the hemi-brains during microglial depletion periods (control, black bars; day 18, blue bars; day 21, red bars). (C) Percentages of $\mathrm{CD} 11 b^{+} \mathrm{CD} 45^{\text {low }} \mathrm{Ly}_{6 \mathrm{C}^{-}} \mathrm{Ly}_{6 \mathrm{G}}{ }^{-}$microglia (/control, $\pm \mathrm{SEM}$ ) during microglial depletion periods (control, black bars; day 18, blue bars; day 21, red bars, $n=11,6,4$, respectively). Statistical significance is indicated as ${ }^{* * * *} p<0.0001$.

2.2. Splenic Red Pulp Macrophages Are Significantly Decreased Following Both Conditional Genetic and Pharmacological Microglial Depletion

We next addressed whether splenic red pulp macrophages were influenced after conditional genetic and pharmacological microglial depletion. $C x 3 c r 1^{\mathrm{CreER} /+} \operatorname{Rosa} 26^{\mathrm{DTA} /+}$ and $C \times 3 c r 1^{\mathrm{CreER} /+}$ mice were 
treated with tamoxifen in order to induce the Cre recombinase and mice were terminated 3 or 7 days later. The splenic flow cytometry gating strategy is depicted in Supplementary Figure S1. We determined that in $\mathrm{C} x 3 \mathrm{cr} 1^{\mathrm{CreER} /+}$ Rosa $26^{\mathrm{DTA} /+}$ mice the numbers and proportions of $\mathrm{F} 4 / 80^{\mathrm{hi}} \mathrm{Ly}^{\mathrm{C}} \mathrm{C}^{-}$splenic red pulp macrophages were significantly decreased 7 days after tamoxifen treatment, the most significant time point of depletion (Figure $2 \mathrm{~A}, \mathrm{~B},{ }^{*} p<0.05,{ }^{* *} p<0.01$ ). Similar findings with reduced numbers and percentages of $\mathrm{F} 4 / 80^{\mathrm{hi}} \mathrm{Ly} 6 \mathrm{C}^{-}$splenic red pulp macrophages were also noted using $290 \mathrm{mg} / \mathrm{kg}$ PLX3397 diet pharmacological-induced microglial depletion. Our results discerned that the numbers and percentages of $\mathrm{F} 4 / 80^{\mathrm{hi}} \mathrm{Ly} 6 \mathrm{C}^{-}$red pulp macrophages in the spleen were significantly fewer 21 days following PLX3397 treatment, the most significant time point of pharmacological microglial depletion, than control group (Figure $2 \mathrm{C}, \mathrm{D}^{* *} p<0.01$ ).
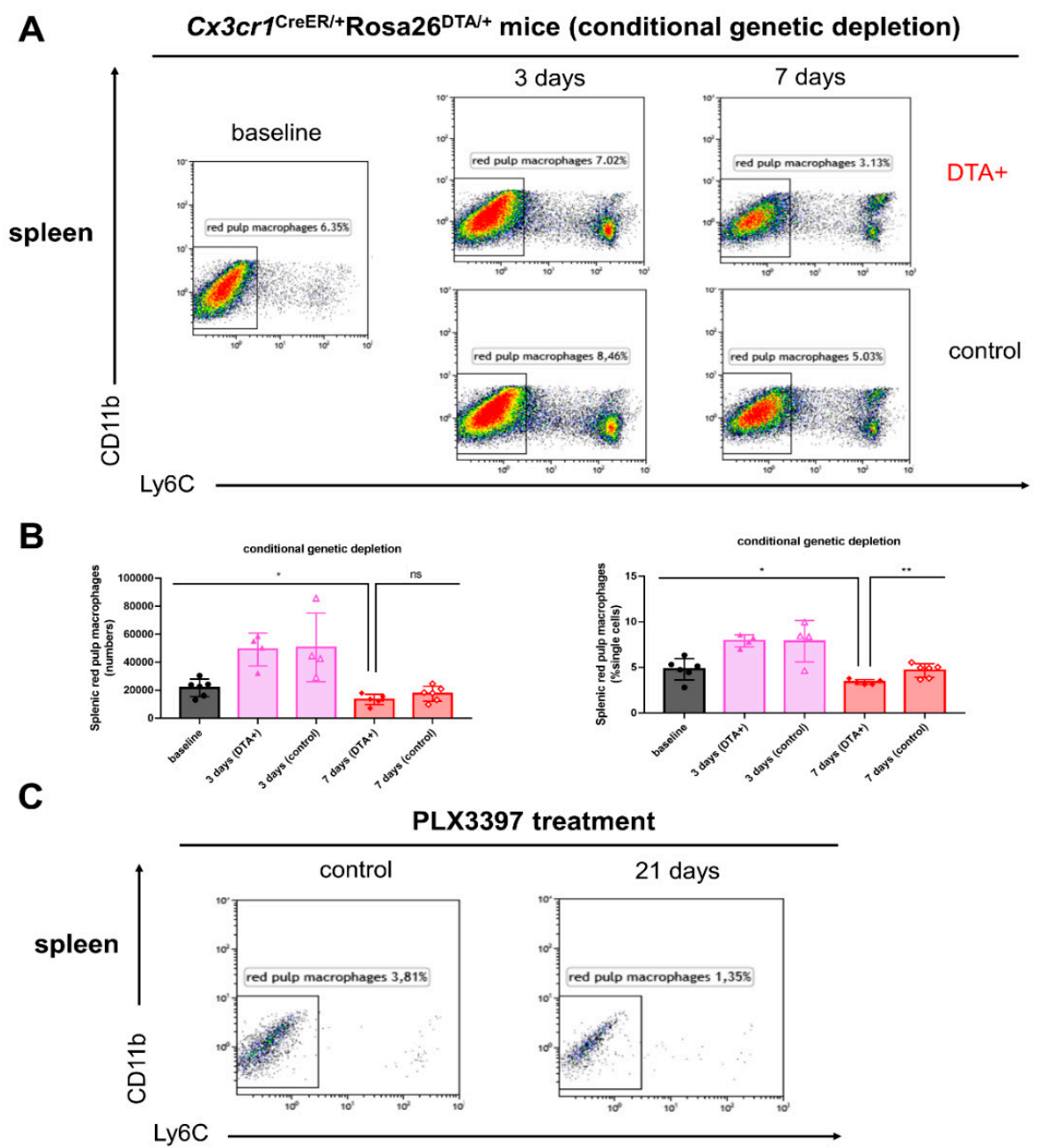

D
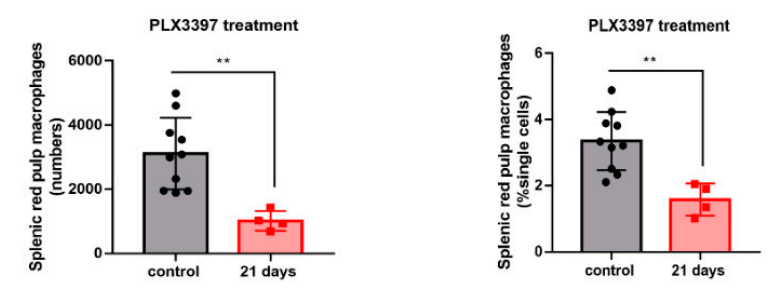

Figure 2. Splenic red pulp macrophages are reduced following both conditional genetic and pharmacological microglial depletion. (A) Representative flow cytometry plots of splenic red pulp macrophages in $\mathrm{C} x 3 \mathrm{cr} 1^{\mathrm{CreER} /+}$ Rosa $26^{\mathrm{DTA} /+}$ and $\mathrm{C} x 3 \mathrm{cr} 1^{\mathrm{CreER} /+}$ mice at days 3 and 7 post tamoxifen injections. Red pulp macrophages were analyzed under the F4/80hi gate. (B) The numbers and percentages of splenic red pulp macrophages $( \pm$ SEM) during conditional genetic microglial depletion 
periods (baseline, black bars; day 3, pink bars; day 7, red bars, $n=6,4,4,6,6$, respectively). (C) Representative flow cytometry plots of splenic red pulp macrophages in C57BL/6NTac mice following $290 \mathrm{mg} / \mathrm{kg}$ PLX3397 diet (21 days). Control mice were treated with normal diet. (D) The numbers and percentages of splenic red pulp macrophages $( \pm$ SEM) during pharmacological microglial depletion periods (control, black bars; day 21, red bars, $n=10,4$, respectively). A total of 400,000 cells from the spleen were run for flow cytometry in this experiment. Statistical significance is indicated as ${ }^{*} p<0.05$ and ${ }^{* *} p<0.01$ (ns: not significant).

2.3. Splenic Ly6Chi Monocytes Are Significantly Increased Following Conditional Genetic Microglial Depletion, but Not Pharmacological Depletion

We next addressed whether splenic Ly6 $\mathrm{C}^{\text {hi }}$ monocytes could also be influenced following both genetic and pharmacological microglial depletion. Unlike reduced numbers of splenic red pulp macrophages, we demonstrated that during conditional genetic microglial depletion periods the numbers and percentages of splenic Ly6 $\mathrm{C}^{\text {hi }}$ monocytes were significantly increased 7 days following tamoxifen treatment (Figure 3A,B ${ }^{* * *} p<0.0001 ;{ }^{* *} p<0.01$ ). The numbers and percentages of splenic Ly6 $\mathrm{C}^{\mathrm{hi}}$ monocytes were not significantly different between $C \times 3 c r 1^{\text {CreER/+ }}$ Rosa26 ${ }^{\mathrm{DTA} /+}$ mice and C $x 3 c r 1^{\text {CreER/+ }}$ mice (Figure 3B). Furthermore, $290 \mathrm{mg} / \mathrm{kg}$ PLX3397-mediated microglial depletion did not significantly alter the numbers and percentages of splenic Ly6C hi monocytes (Figure 3C,D).

\subsection{Splenic CD4 ${ }^{+}$T Cells and NK Cells Are Affected Following Conditional Genetic and Pharmacological Microglial Depletion}

Our results demonstrated that during both conditional genetic and pharmacological microglial depletion periods the numbers of splenic $\mathrm{CD}^{+} \mathrm{T}$ cells were significantly decreased after 7 days (Figure $4 \mathrm{~A}, \mathrm{~B}^{* * *} p<0.001$ ) and 21 days (Figure $4 \mathrm{D}, \mathrm{E}^{*} p<0.05$ ), respectively. Furthermore, the numbers and percentages of splenic NK cells were significantly reduced following both conditional genetic and pharmacological microglial depletions (Figure $4 \mathrm{C}, \mathrm{F}^{* * * *} p<0.0001,{ }^{*} p<0.05$ ).

\subsection{Reduced Numbers of Monocytes in the Circulation Following Conditional Genetic and Pharmacological Microglial Depletion}

We explored the dynamic changes of circulating monocytes following conditional genetic and pharmacological microglial depletions. The blood gating strategy is depicted in Supplementary Figure S2. Our results indicated that the numbers of both circulating classical Ly6 $\mathrm{C}^{\text {hi }}$ monocytes and non-classical Ly6C low monocytes were significantly decreased even when using the PLX3397 research diet at a lower concentration of $75 \mathrm{mg} / \mathrm{kg}$ (Figure 5A,B ${ }^{* *} p<0.01,{ }^{* * *} p<0.001$ and ${ }^{* * *} p<0.0001$ ). For conditional genetic microglial depletion, the numbers of circulating $\mathrm{Ly}_{6 \mathrm{G}^{+}}$neutrophils were gradually increased in both groups as a result of tamoxifen injections (Figure $5 \mathrm{C}$ ). The numbers of circulating $\mathrm{Ly}^{6} \mathrm{G}^{+}$neutrophils reached the highest levels after 7 days, but returned to the baseline level one month later (Figure 5C). We also observed that numbers of circulating classical Ly6C hi monocytes and non-classical Ly6C ${ }^{\text {low }}$ monocytes in the circulation were gradually decreased 7 days after tamoxifen injections (Figure 5C $\left.{ }^{* *} p<0.01\right)$. Interestingly, while classical Ly6 $\mathrm{C}^{\mathrm{hi}}$ monocyte numbers returned to the baseline level one month later, non-classical Ly6C ${ }^{\text {low }}$ monocytes did not (Figure 5C). No significant differences in numbers of circulating classical Ly6 $\mathrm{C}^{\text {hi }}$ monocytes and non-classical Ly6 $\mathrm{C}^{\text {low }}$ monocytes were noted in $\mathrm{C} \times 3 \mathrm{cr} 1^{\mathrm{CreER} /+}$ control mice during microglial depletion periods (Figure $5 \mathrm{C}$ ). 
A C $\times 3 c r 1^{\mathrm{CreER} /+} \mathrm{Rosa}^{\mathrm{D}} 6^{\mathrm{DTA} /+}$ mice (conditional genetic depletion)

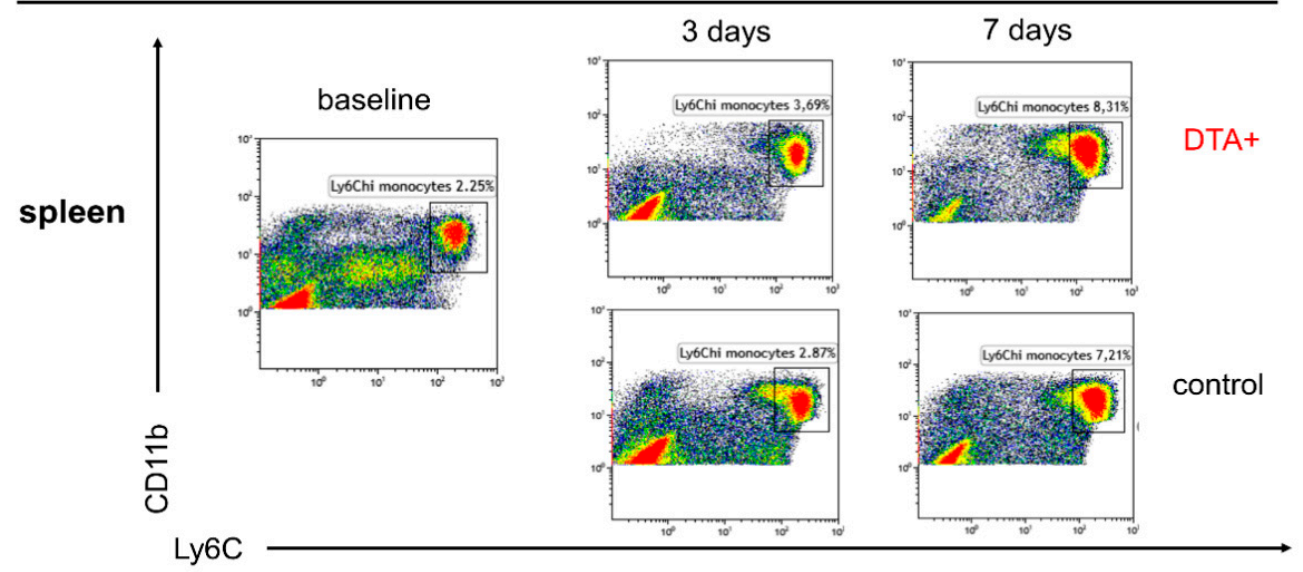

B
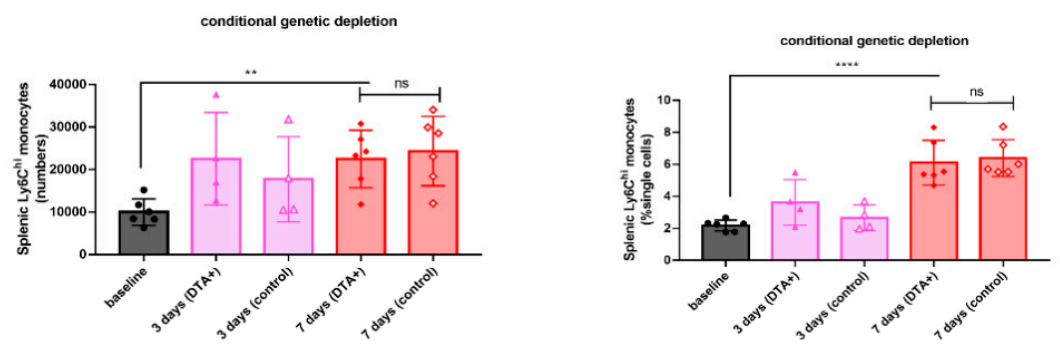

C

PLX3397 treatment

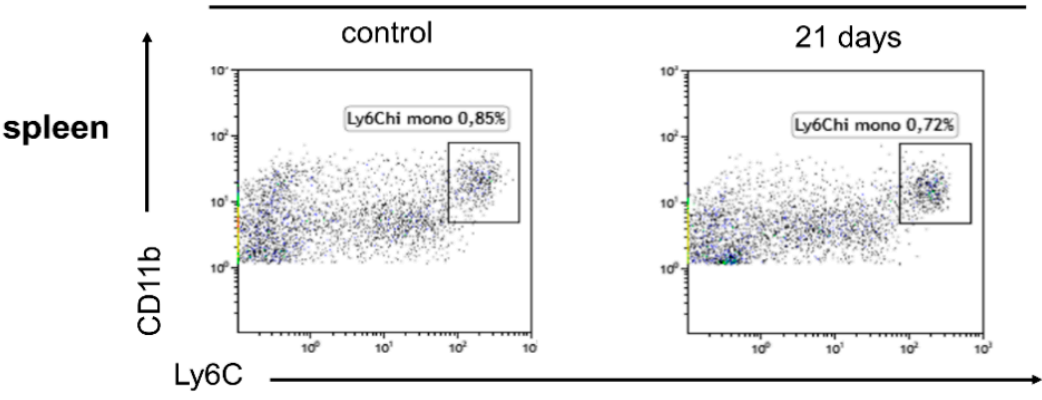

D
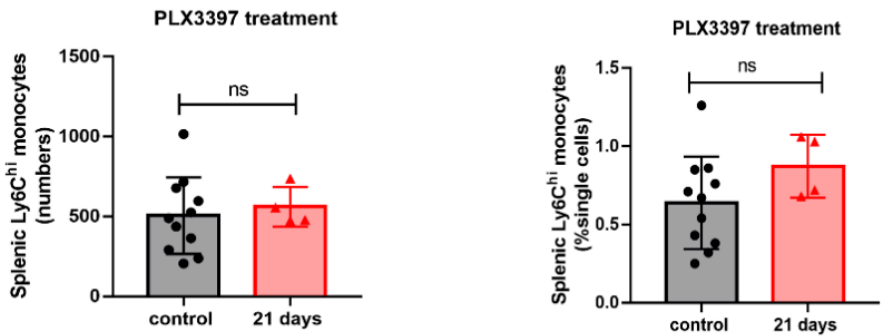

Figure 3. Splenic Ly6 $\mathrm{C}^{\text {hi }}$ monocytes are increased following conditional genetic microglial depletion, but not after pharmacological depletion. (A) Representative flow cytometry plots of $\mathrm{CD} 11 \mathrm{~b}^{+} \mathrm{Ly}_{6 \mathrm{G}}{ }^{-} \mathrm{Ly} 6 \mathrm{C}^{\mathrm{hi}}$ splenic monocytes in $\mathrm{C} x 3 \mathrm{cr} 1^{\mathrm{CreER} /+}$ Rosa $26^{\mathrm{DTA} /+}$ and $\mathrm{C} x 3 \mathrm{cr} 1^{\mathrm{CreER} /+}$ mice at days 3 and 7 post tamoxifen injections. (B) The numbers and percentages of splenic Ly6C hi monocytes $( \pm \mathrm{SEM})$ in the spleen during conditional genetic microglial depletion periods (baseline, black bars; day 3, pink bars; day 7, red bars, $n=6,4,4,6,6$, respectively). (C) Representative flow cytometry plots of splenic Ly6C ${ }^{\text {hi }}$ monocytes in C57BL/6NTac mice following PLX3397 diet (21 days) at a dose of $290 \mathrm{mg} / \mathrm{kg}$. Control mice were treated with normal diet. (D) The numbers and percentages of splenic Ly6 $\mathrm{C}^{\text {hi }}$ monocytes $( \pm \mathrm{SEM})$ during pharmacological microglial depletion periods (control, black bars; day 21, red bars, $n=11,4$, respectively). Statistical significance is indicated as ${ }^{* *} p<0.01$ and ${ }^{* * *} p<0.0001$ (ns: not significant). 
A Cx $3 c 1^{\text {CreER/+}}{ }^{\text {Rosa226 }}{ }^{\mathrm{DTA} /+}$ mice (conditional genetic depletion)

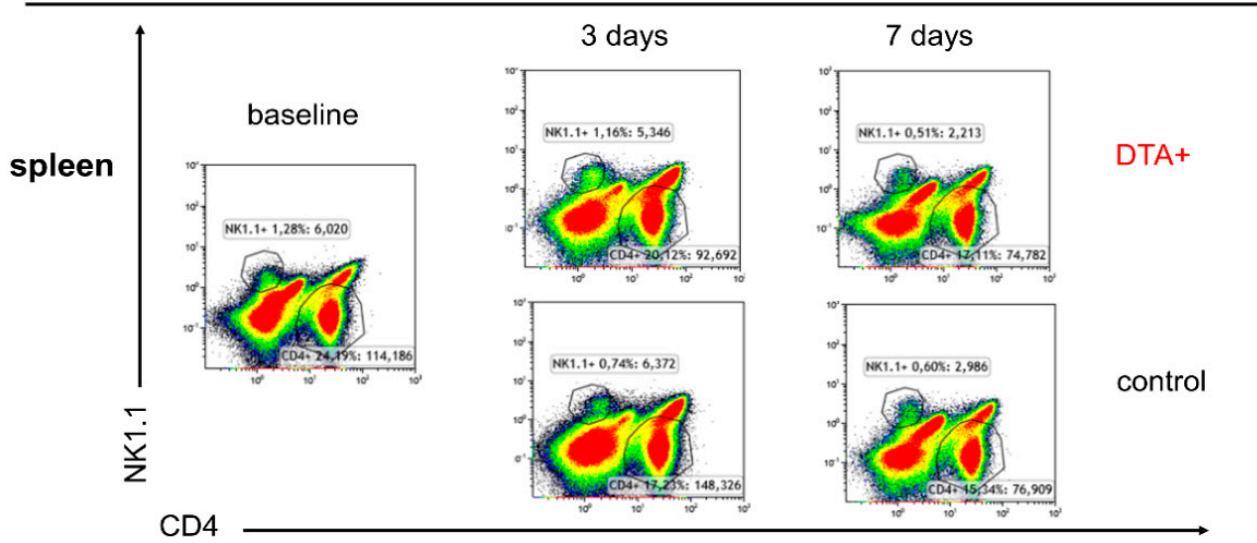

B

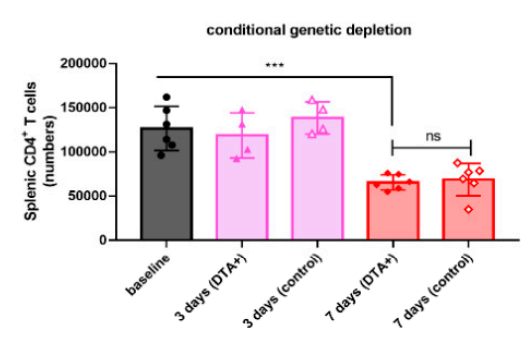

C

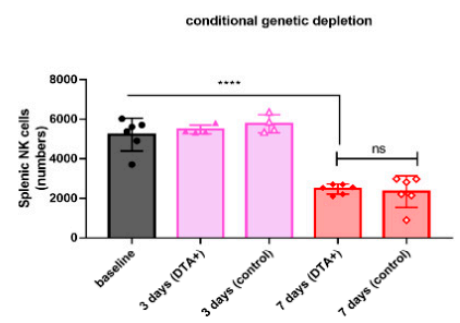

D

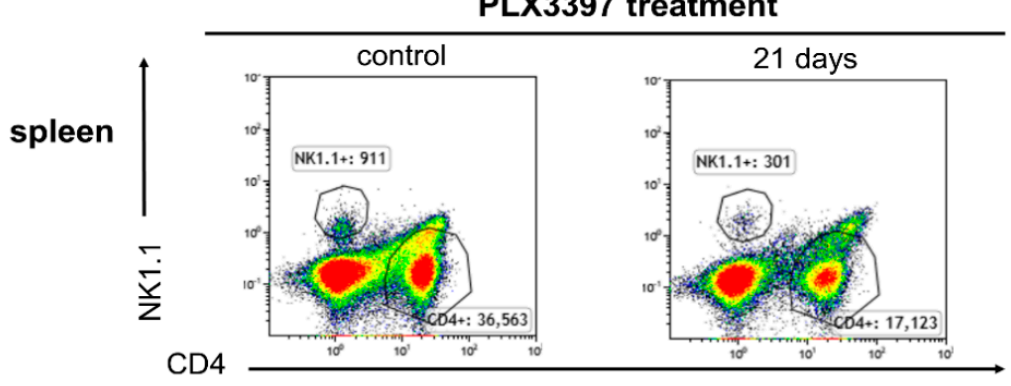

E
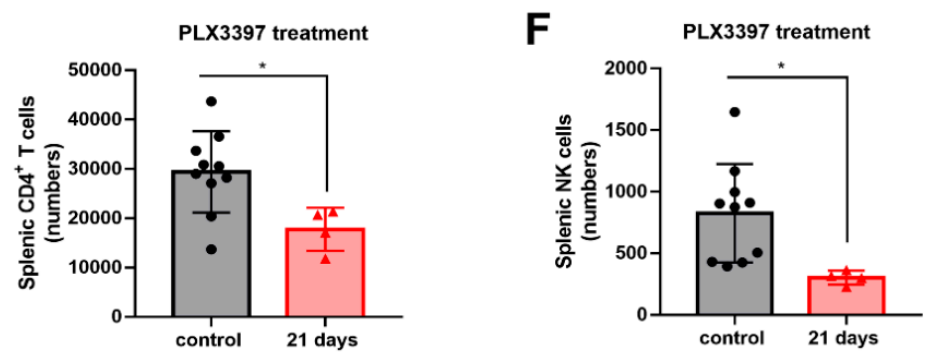

Figure 4. Splenic $\mathrm{CD}^{+}{ }^{+} \mathrm{T}$ cells and NK cells are affected following conditional genetic and pharmacological microglial depletion. (A) Representative flow cytometry plots of splenic $\mathrm{CD}^{+}$ $\mathrm{T}$ cells and NK1.1 ${ }^{+}$cells in $\mathrm{C} x 3 \mathrm{cr} 1^{\mathrm{CreER} /{ }^{+}}$Rosa2 $6^{\mathrm{DTA} /+}$ and $\mathrm{C} x 3 \mathrm{cr}{ }^{\mathrm{CreER} /+}$ mice 3 and 7 days after tamoxifen injections. (B,C) Quantitative analysis of splenic CD4 ${ }^{+} \mathrm{T}$ cells and NK1.1 $1^{+}$cells $( \pm$SEM) during conditional genetic microglial depletion periods (baseline, black bars; day 3, pink bars; day 7 , red bars, $n=6,4,4,6,6$, respectively). (D) Representative flow cytometry plots of splenic CD4 ${ }^{+} \mathrm{T}$ cells and NK1.1 ${ }^{+}$cells in C57BL/6NTac mice following PLX3397 diet (21 days) at a dose of $290 \mathrm{mg} / \mathrm{kg}$. Control mice were treated with normal diet. (E,F) Quantitative analysis of splenic CD4 ${ }^{+} \mathrm{T}$ cells and $\mathrm{NK} 1.1^{+}$cells $( \pm \mathrm{SEM})$ during pharmacological microglial depletion periods (control, black bars; day 21, red bars, $n=10,4$, respectively). Statistical significance is indicated as ${ }^{*} p<0.05,{ }^{* * *} p<0.001$ and **** $p<0.0001$ (ns: not significant). 
A 21 days after PLX3397 treatment

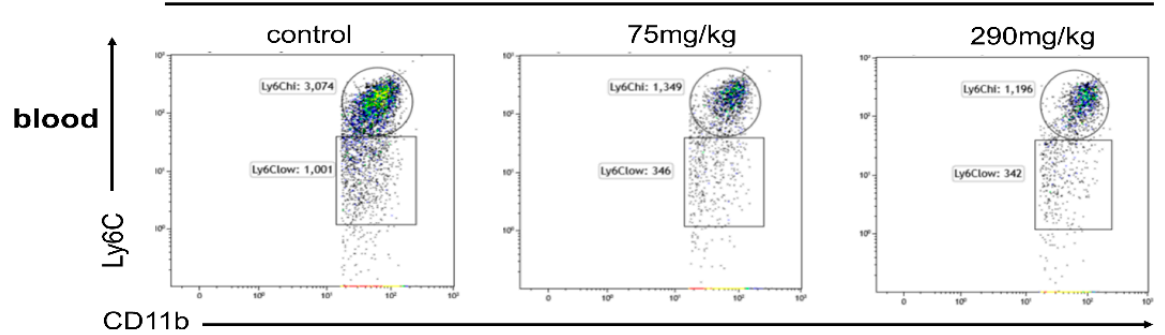

B PLX3397 treatment
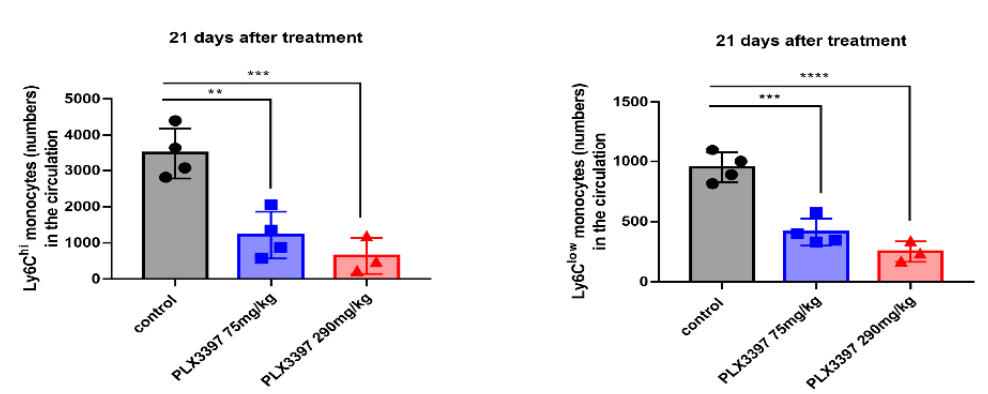

C Cx3cr1 ${ }^{\mathrm{CreER} /+}$ Rosa26 $^{\mathrm{DTA} /+}$ mice (conditional genetic depletion)
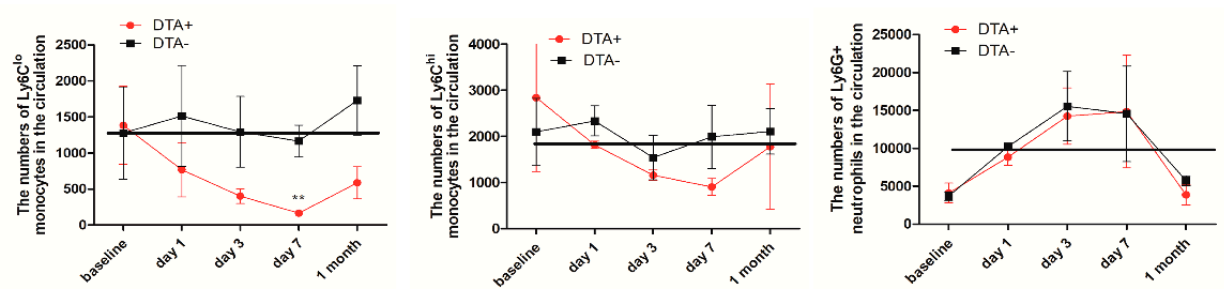

Figure 5. The numbers of circulating monocytes are reduced following both conditional genetic and pharmacological microglial depletion. (A) Representative flow cytometry plots of Ly6Chi and Ly6Clow monocytes in the circulation following 21 consecutive days of PLX3397 diet treatment at different doses of $75 \mathrm{mg} / \mathrm{kg}$ and $290 \mathrm{mg} / \mathrm{kg}$, respectively. Control mice were treated with normal diet. (B) The numbers of circulating Ly6C hi and Ly6C ${ }^{\text {low }}$ monocytes $( \pm \mathrm{SEM})$ during pharmacological microglial depletion periods (control, black bars; 75 mg/kg PLX3397 treatment, blue bars; 290 mg/kg PLX3397 treatment, red bars, $n=4$, 4 , 3, respectively). (C) Kinetic changes of circulating Ly6C hi monocytes, Ly6C ${ }^{\text {low }}$ monocytes and $\mathrm{Ly}^{\mathrm{h}} \mathrm{G}^{+}$ neutrophils in $\mathrm{C} x 3 \mathrm{cr} 1^{\mathrm{CreER} /+}$ Rosa2 $6^{\mathrm{DTA} /+}$ mice treated with tamoxifen (baseline, $n=6 ; C x 3 c r 1^{\mathrm{CreER} /+}$ mice, black bars; $n=4,4,4,5$, respectively; $C x 3 c r 1^{\mathrm{CreER} /+} \operatorname{Rosa2} 6^{\mathrm{DTA} /+}$ mice, red bars; $n=3,4,4,3$, respectively). Statistical significance is indicated as ${ }^{* *} p<0.01,{ }^{* * *} p<0.001$ and ${ }^{* * * *} p<0.0001$ (ns: not significant).

\subsection{Dose-Dependent Peripheral Effects Following Pharmacological Microglial Depletion}

We demonstrated that both splenic red pulp macrophages and circulating monocytes could be affected during microglial depletion. Given that different concentrations of pharmacological inhibitors have previously been used in different previous studies, we next explored whether these peripheral effects were concentration-dependent and occurred at an earlier time point. C57BL/6NTac mice were thus fed with two distinct doses of PLX3397 diet (290 mg/kg and $75 \mathrm{mg} / \mathrm{kg})$. The lower dose of PLX3397 treatment failed to effectively deplete microglia (Supplementary Figure S3). Consistent with our previous findings, we observed that the percentages splenic red pulp macrophages were significantly reduced 7 days after $290 \mathrm{mg} / \mathrm{kg}$ PLX3397 treatment, but not in the $75 \mathrm{mg} / \mathrm{kg}$ low dose group (Figure $6 \mathrm{~A}, \mathrm{~B} * p<0.05$ ). Clearly, the numbers and proportions of splenic monocytes were significantly reduced 7 days after PLX3397 treatment with a dose of $290 \mathrm{mg} / \mathrm{kg}$ (Figure $6 \mathrm{C}, \mathrm{D}^{* *} p<0.01 ; * * * 00.001$ ). Additionally, the numbers of splenic monocytes were also significantly decreased with the lower dose PLX3397 diet (Figure 6D ${ }^{* *} p<0.01$ ). 
A 7 days after PLX3397 treatment

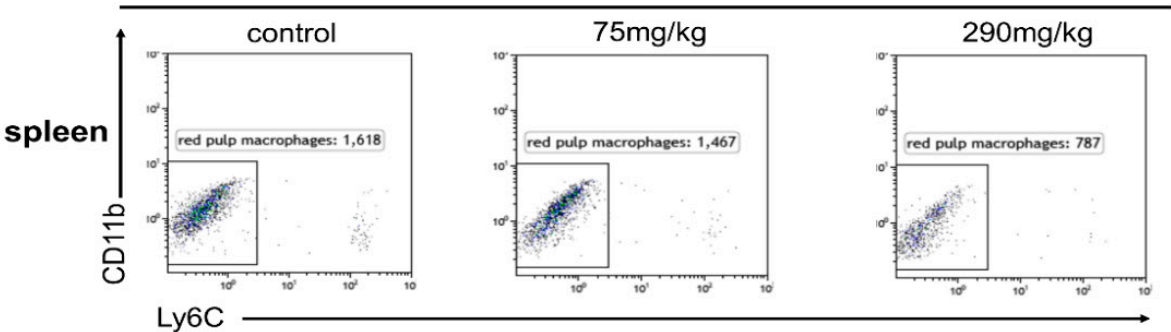

B
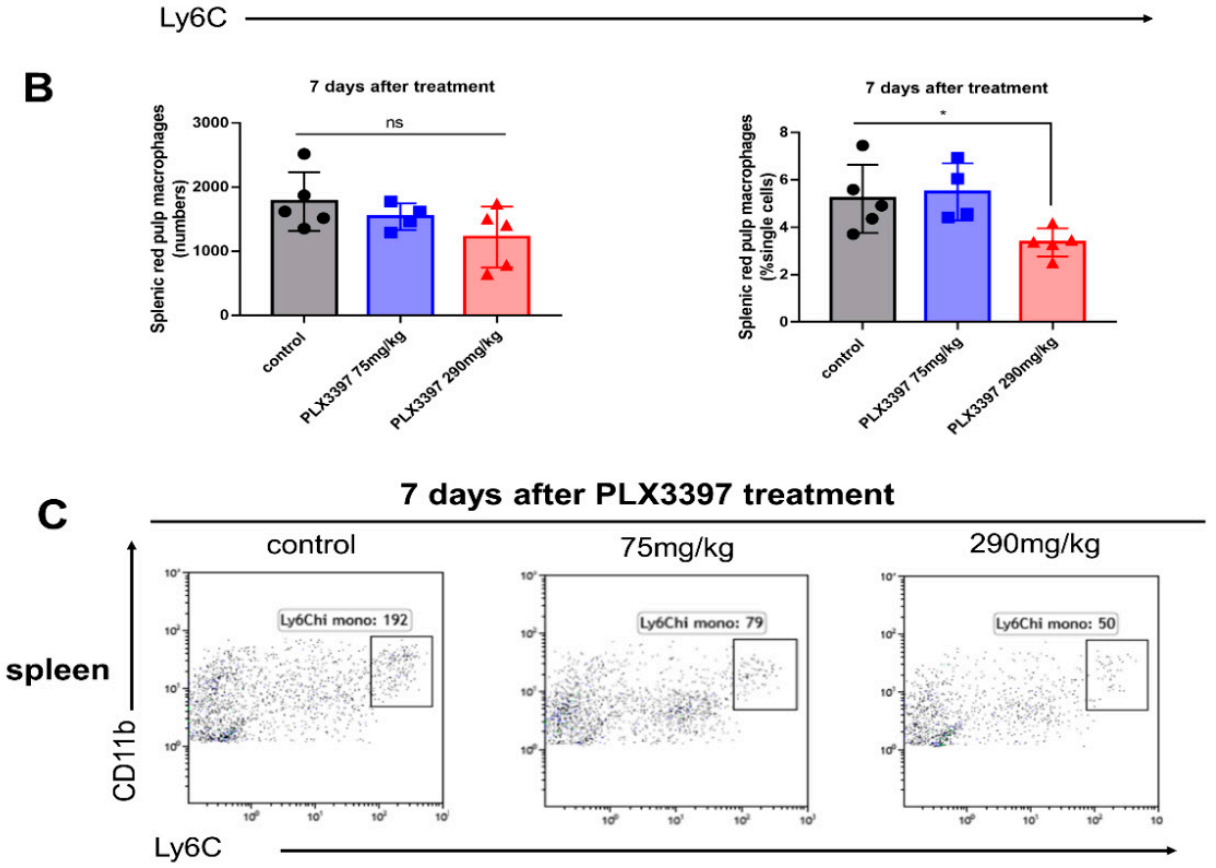

D
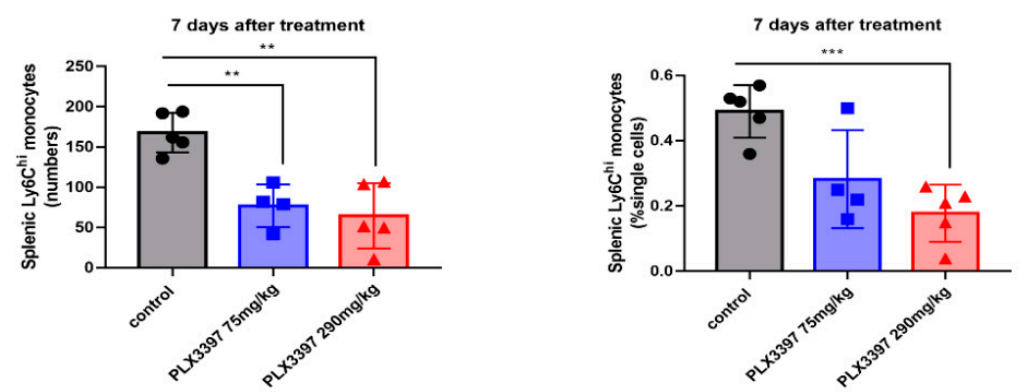

Figure 6. Dose-dependent peripheral effects following pharmacological microglial depletion. (A) Representative flow cytometry plots of splenic red pulp macrophages following 7 consecutive days of PLX3397 diet treatment with different doses of $75 \mathrm{mg} / \mathrm{kg}$ and $290 \mathrm{mg} / \mathrm{kg}$, respectively. Control mice were treated with normal diet. (B) The numbers and percentages of red pulp macrophages $( \pm$ SEM) in the spleen following PLX3397 diet with different doses (control, black bars; 75 mg/kg PLX3397 diet, blue bars; $290 \mathrm{mg} / \mathrm{kg}$ PLX3397 diet, red bars, $n=5$, 4, 5, respectively). (C) Representative flow cytometry plots of splenic Ly6Chi monocytes following 7 consecutive days of PLX3397 diet treatment with different doses. Control mice were treated with normal diet. (D) The numbers and percentages of splenic Ly6C ${ }^{\text {hi }}$ monocytes ( \pm SEM) following PLX3397 with different doses (control, black bars; 75 mg/kg PLX3397 diet, blue bars; $290 \mathrm{mg} / \mathrm{kg}$ PLX3397 diet, red bars, $n=5,4,5$, respectively). Statistical significance is indicated as ${ }^{*} p<0.05,{ }^{* *} p<0.01$ and ${ }^{* *} p<0.001$.

\subsection{Intracisternal Injection of PLX3397 Does Not Exert Significant Influence on Splenic Myeloid Cells}

To avoid unnecessary peripheral effects during microglial depletion we next assessed if intracisternal injection of PLX3397 (10 $\mu \mathrm{L}$ per injection for two consecutive days) had any effects on 
splenic myeloid cells. However, this method caused only a partial depletion of microglia (not shown). Unlike systemic administration of the PLX3397 diet, the numbers and percentages of splenic red pulp macrophages (Figure 7A,B) and monocytes (Figure 7C,D) did not alter significantly following intracisternal injections of PLX3397.

A

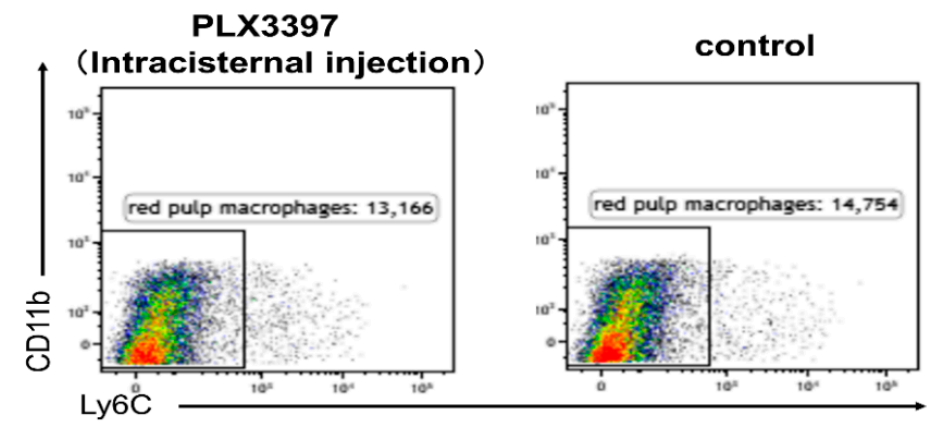

B

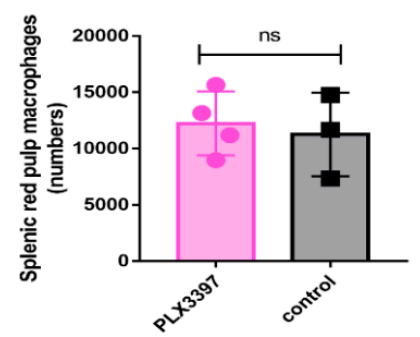

PLX3397

C

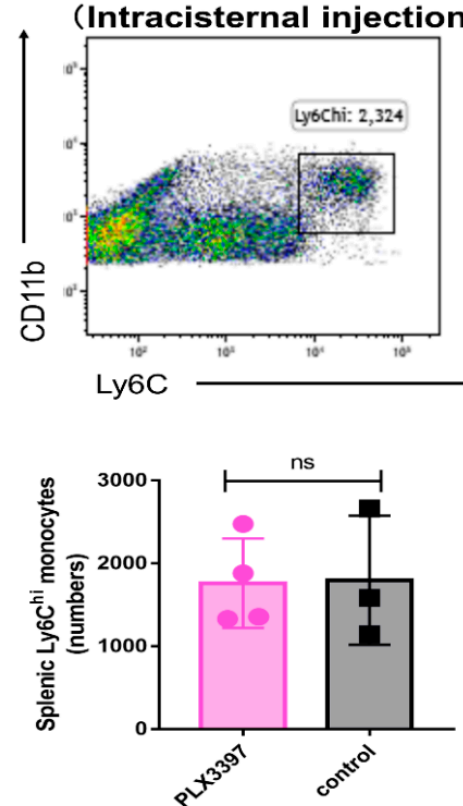

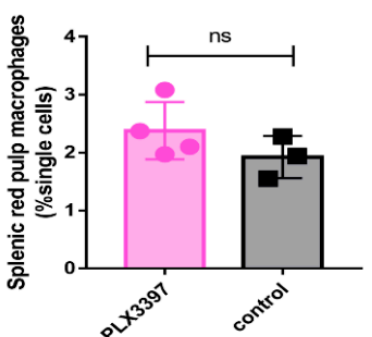

control
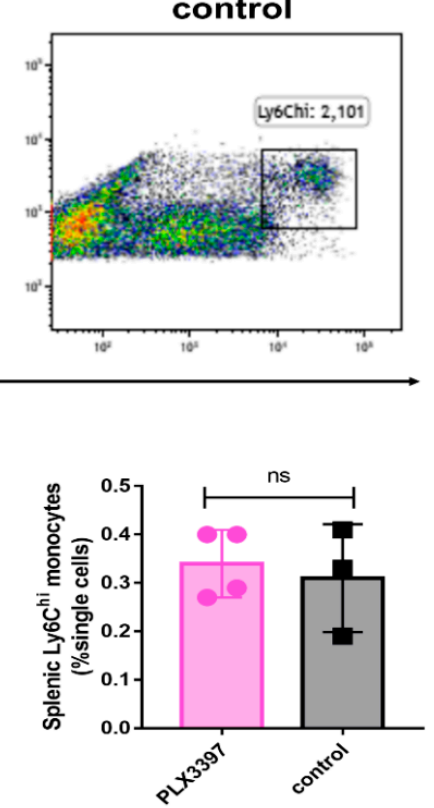

Figure 7. Intracisternal injection of PLX3397 does not exert a significant effect on splenic myeloid cells. (A,B) The number and percentage of red pulp macrophages $( \pm$ SEM) in the spleen following intracisternal injection of PLX3397 (PLX3397 treatment group, pink bars; control, black bars, $n=4$, 3 , respectively). (C,D) The number and percentage of splenic Ly6C $\mathrm{C}^{\text {hi }}$ monocytes ( \pm SEM) following intracisternal PLX3397 treatment (PLX3397 treatment group, pink bars; control, black bars, $n=4,3$, respectively). ns: not significant. 


\section{Discussion}

In this study, we demonstrated that both conditional genetic and pharmacological microglial depletion approaches have significant effects on circulating monocytes and peripheral tissue macrophages, and that these effects can be abrogated by direct delivery of pharmacological inhibitors directly into the CNS. These findings should be taken into due consideration in the interpretation of microglial depletion results and in the planning for clinical translation of microglial replacement therapy.

Unlike other tissue macrophages derived from the bone marrow and fetal liver, microglia arise exclusively from the yolk sac during early neurodevelopment [27], exhibiting a distinct transcriptomic profile (including P2ry12 and Tmem119) [28]. Recent sophisticated analysis of protein-coding genes across different species convincingly demonstrated that a variety of microglial signature genes are also highly enriched in the selective peripheral organs, such as in the circulation and lymphoid tissues [29].

It is documented that classical monocytes have a low expression of CX3CR1, while non-classical monocytes exhibit high expression. In support of this, our results demonstrated that numbers of circulating classical Ly6 $\mathrm{C}^{\text {hi }}$ monocytes and non-classical Ly6C $\mathrm{C}^{\text {low }}$ monocytes significantly decreased in $\mathrm{C} \times 3 \mathrm{cr} 1^{\mathrm{CreER} /+}$ Rosa $26^{\mathrm{DTA} /+}$ mice following tamoxifen treatment, with non-classical Ly6C $\mathrm{C}^{\text {low }}$ monocytes being most affected. Consistent with this idea, systemic administration of a high-affinity inhibitor of CX3CR1 (AZD8797) can effectively block infiltrating CX3CR1+ leukocytes, but not CX3CR1-expressing microglia in the CNS, subsequently relieving clinical symptoms and inhibiting the progression of experimental autoimmune encephalomyelitis, an animal model of multiple sclerosis [30]. Furthermore, the spleen contains a reservoir of monocytes which can be released upon tissue injury. One previous study reported that 1 day after the administration of diphtheria toxin in Cx3cr1-DTR mice, the numbers of activated macrophages in the cochlea and spleen following systemic lipopolysaccharide injections were significantly reduced, suggesting that peripheral CX3CR1-expressing macrophages were affected using this conditional genetic tool [11]. In our current study, peripheral effects were measured within one week after tamoxifen treatment, with splenic Ly $6 \mathrm{C}^{\text {hi }}$ monocytes being increased in both $C x 3 c r 1^{\mathrm{CreER} /+}$ Rosa $26^{\mathrm{DTA} /+}$ and $\mathrm{C} x 3 c r 1^{\mathrm{CreER} /+}$ mice. At the same time, circulating Ly $6 \mathrm{G}^{+}$neutrophils reached the highest levels 7 days after tamoxifen injections. In this case, peripheral effects caused by tamoxifen alone cannot be ruled out in our study. Our results also indicated that both the numbers and percentages of splenic red pulp macrophages were significantly decreased in $\mathrm{C} x 3 \mathrm{cr} 1^{\mathrm{CreER} /+} \mathrm{Rosa2} 6^{\mathrm{DTA} /+}$ mice following tamoxifen treatment, indicating that tissue resident macrophages can be affected following conditional genetic microglial depletion. Further studies using conditional genetic microglial depletion including $C \times 3 c r 1^{\mathrm{CreER} /+}$ Rosa $26^{\mathrm{DTA} /+}$ and $C \times 3 c r 1$-DTR are needed to verify our findings in other peripheral organs.

The survival, maintenance and proliferation of microglia is critically dependent on close interplay between CSF-1 and its receptor CSF1R. This receptor is a tyrosine kinase, and despite mainly being expressed on microglia in the CNS, it can also be expressed on other tissue macrophages and peripheral monocytes. Some previous studies concluded that systemic administration of CSF1R inhibitors exerted limited influence on other immune cells in the periphery [23], with dietary PLX3397 at a dose of $290 \mathrm{mg} / \mathrm{kg}$ not substantially altering the percentages of granulocytes and monocytes in the spleen and blood [18]. However, this is not a consistent finding. In the condition of obesity, PLX3397 (50 mg/kg) provided via oral gavage every second day for 21 days significantly decreased the numbers of macrophages in the adipose tissue, but not of circulating myeloid cells [31]. A PLX5562 diet at a concentration of $1200 \mathrm{mg} / \mathrm{kg}$ for 21 days significantly depleted macrophages and monocytes in the circulation and liver [25]. One interpretation of these disparate phenomena is that different doses and durations of PLX3397 treatment were used in different studies. It has also been recently reported that PLX3397 treatment at a high dose of $400 \mathrm{mg} / \mathrm{kg}$ significantly altered blood cell phenotyping [32]. Specifically, the numbers of red blood cells, hemoglobin, platelets, dendritic cells and Ly6C $\mathrm{C}^{-}$monocytes were significantly reduced during microglial depletion via PLX3397 treatment [32]. One recent study suggested that CSF1R inhibitor PLX5622 is not CNS-specific, with peritoneum, lung, and liver tissue macrophages being affected, with $\mathrm{CD} 45^{+} \mathrm{CD} 11 \mathrm{~b}^{+} \mathrm{CD} 106^{+}$splenic macrophages not being influenced 
by the treatment [26]. In contrast, our results determined that the numbers and percentages of splenic red pulp macrophages were significantly reduced after PLX3397 treatment at a dose of $290 \mathrm{mg} / \mathrm{kg}$ for 21 days, which represents a widely used dose in research settings. At this time point, reduced numbers of monocytes in the circulation were also recorded. Collectively, systemic administration of CSF1R inhibitors cannot only deplete microglia in the CNS, but also prohibit the committed precursors of peripheral cells. In this case, the ability of circulating monocytes to contribute to the newly repopulated microglial pool after the treatment of CSF1R inhibitors might be reduced.

Overall, our results suggest that there are significant effects on peripheral immune cells following systemic administration of CSF1R inhibitor PLX3397, which has been mostly ignored previously. Furthermore, conditional genetic microglial depletion also exerts effects on peripheral immunity. These may be due to either tamoxifen injections or additional peripheral targets, but also indicate that not only the intended organ should be considered in the use of cell-specific depletion models. Peripheral immune cells also play an important role in the pathogenesis of many diseases and these peripheral effects may lead to potential adverse effects. In addition, the engraftment of peripheral monocytes into the CNS in certain microglial depletion models has added the complexity. Thus, clinical interpretation of microglial depletion studies in disease conditions should be considered with caution. Further monitoring is needed, particularly in ongoing clinical trials [33].

\section{Materials and Methods}

\subsection{Ethics Statement}

All experiments in this study were approved and performed in accordance with the guidelines from the Swedish National Board for Laboratory Animals and the European Community Council Directive (86/609/EEC) under an ethical permit granted by StockholmNord on 11 July 2019.

\subsection{Animals}

C $x 3$ cr $1^{\mathrm{CreER} /+}$ (Jax) and Rosa26 ${ }^{\mathrm{DTA}}$ (Jax) mice were purchased from the Jackson Laboratory. $\mathrm{C} x 3 \mathrm{cr} 1^{\mathrm{CreER} /+}$ mice and Rosa26 ${ }^{\mathrm{DTA}}$ mice were bred to obtain $\mathrm{C} \times 3 \mathrm{cr} 1^{\mathrm{CreER} /+} \mathrm{Rosa26} 6^{\mathrm{DTA} /+}$ mice that were used for conditional genetic microglial depletion. $\mathrm{C} x 3 \mathrm{cr} 1^{\mathrm{CreER} /+}$ mice served as the control group. C57BL/6NTac mice (Taconic, Denmark) were bred at Karolinska University Hospital. All experimental mice were maintained under a specific pathogen-free, regulated light/dark schedule and temperature conditions. All experimental mice had free access to standard rodent chow and water. For the PLX3397 dose titration experiments, C57BL/6NTac female mice aged between 5- and 7-week-old were used, while both male and female mice were used for all other experiments.

\subsection{Tamoxifen Treatment}

To induce the Cre recombinase in $C x 3 c r 1^{\mathrm{CreER} /+} \operatorname{Rosa} 26^{\mathrm{DTA} /+}$ mice, animals were treated with tamoxifen (TAM; Sigma, T5648-1G, St Louis, USA). Tamoxifen was suspended in the corn oil (Sigma, C8267-500ML, St Louis, MO, USA). Both $C x 3 c r 1^{\mathrm{CreER} /+} \operatorname{Rosa} 26^{\mathrm{DTA} /+}$ and $\mathrm{C} x 3 \mathrm{cr} 1^{\mathrm{CreER} /+}$ mice were administered $5 \mathrm{mg}(200 \mu \mathrm{L})$ tamoxifen subcutaneously on three consecutive days, as previously described by our research group $[9,10]$.

\subsection{PLX3397 Treatment}

PLX3397 (Pexidartinib, HY-16749, MedChemExpress, USA) was formulated into either $290 \mathrm{mg} / \mathrm{kg}$ or $75 \mathrm{mg} / \mathrm{kg}$ standard diet (provided by SAFE Nutrition Service, France). PLX3397 diet was administered for 7,18 or 21 consecutive days depending on research purposes to C57BL/6NTac mice. Mice in the control group were fed with a normal diet. 


\subsection{Intracisternal Injection of PLX3397}

PLX3397 (Selleck, S7818, USA) were dissolved in 10\% DMSO and 90\% $100 \mathrm{mg} / \mathrm{mL}$ Captisol (Selleck, S4592, USA) at a concentration of $100 \mu \mathrm{M}$, and were delivered to the cerebrospinal fluid of mice vial intracisternal injection ( $10 \mu \mathrm{L}$ per injection) under isoflurane inhalation (once per day for consecutive two days).

\subsection{Preparation of Single Cell Suspensions from Blood, Spleen and CNS Tissues}

Mice were deeply anesthetized by injecting $100 \mu \mathrm{g}$ pentobarbital intraperitoneally. Blood was collected from the right ventricle prior to perfusion. Briefly, $200 \mu \mathrm{L}$ blood were collected into tubes containing ethylenediaminetetraacetic acid (EDTA, E7889, Sigma, Sweden), lysed in ACK buffer (A1049201, Gibco) and then centrifuged. The pellet was resuspended in cold PBS and used for staining. Spleens were dissected and cell suspensions prepared by mechanical dissociation in ice-cold PBS by passing through $40 \mu \mathrm{m}$ cell strainers (734-0002, VWR; Stockholm, Sweden). Mice were perfused through the left cardiac ventricle using ice-cold PBS. Whole brain and spinal cord were removed and minced with a surgical disposable scalpel (Medicarrier AB, Sweden), followed by enzymatic digestion using Collagenase (11088866001, Roche, Sweden) and DNAse (000000010104159001, Roche, Sweden). Myelin was removed using 38\% Percoll (P1644-1L, Sigma, Sweden).

\subsection{Flow Cytometry}

Single cell suspensions were plated in 96-well V-bottom plates and stained at $4{ }^{\circ} \mathrm{C}$ for $20 \mathrm{~min}$. Dead cells were removed using Live/DeadTM Fixable Near-IR Dead Cell Stain Kit (Invitrogen, Thermo Fisher Scientific, Stockholm, Sweden) in each panel. The following antibody panels were used: 1. For CNS cells analysis, single cell suspensions were incubated with Percp-Cy5.5-CD11b (clone: M1/70, BioLegend, San Diego, CA, USA), PE/Cy7-CD45 (clone: 30-F11, BioLegend, San Diego, CA, USA), PE-Ly6C (clone: HK1.4, BioLegend, San Diego, CA, USA), V450-Ly6G (clone: 1A8, BD Biosciences, Sweden), APC-F4/80 (clone: BM8, BioLegend, San Diego, CA, USA) and Alexa Fluor700-MHCII (clone: M5/114.15.2, BioLegend, San Diego, CA, USA). 2. For splenic cells analysis, single cell suspensions were incubated with FITC-CD11b (clone: M1/70, BioLegend, San Diego, CA, USA), PE-Ly6C (clone: HK1.4, BioLegend, San Diego, CA, USA), V450-Ly6G (clone: 1A8, BD Biosciences, Sweden), PE/Cy7-F4/80 (clone: BM8, BioLegend, San Diego, CA, USA), V500-CD4 (clone: RM4-5, BioLegend, San Diego, CA, USA) and PCP5.5-NK1.1 (clone: PK136, BioLegend, San Diego, CA, USA). 3. For blood cells analysis, single cell suspensions were incubated with Percp-Cy5.5-CD11b (clone: M1/70, BioLegend, San Diego, CA, USA), PE/Cy7-CD45 (clone: 30-F11, BioLegend, San Diego, CA, USA), PE-Ly6C (clone: HK1.4, BioLegend, San Diego, CA, USA), V450-Ly6G (clone: 1A8, BD Biosciences, Sweden), APC-F4/80 (clone: BM8, BioLegend, San Diego, CA, USA) and FITC-CX3CR1 (clone: SA011F11, BioLegend, San Diego, CA, USA). Cells were acquired using a Gallios flow cytometer (Beckman Coulter, Indianapolis, USA) and analyzed using Kaluza software (Beckman Coulter, Indianapolis, USA).

\subsection{Statistical Analysis}

Statistical analysis was conducted using GraphPad software 8 (San Diego, CA, USA). Comparisons between two groups were made with Mann-Whitney tests. Comparisons of data among multiple groups were analyzed by one-way analysis of variance (ANOVA). Error bars are presented as SEM. Differences at $p<0.05$ were considered to be statistically significant.

Supplementary Materials: Supplementary materials can be found at http://www.mdpi.com/1422-0067/21/22/8603/ s1. Supplementary Figure S1: Splenic flow cytometry gating strategy. Supplementary Figure S2: Gating strategy of monocytes in the circulation. Supplementary Figure S3: Lower dose of PLX3397 treatment fails to effectively deplete microglia. 
Author Contributions: Conceptualization, J.H. and R.A.H.; methodology, J.H., Y.F., K.Z. (Kai Zhou) and K.Z. (Keying Zhu); resources, H.L., K.B. and R.A.H.; writing-original draft preparation, J.H.; writing-review and editing, Y.F., K.Z. (Kai Zhou), H.L., X.-M.Z. and R.A.H.; supervision, H.L., X.-M.Z. and R.A.H.; funding acquisition, R.A.H. All authors have read and agreed to the published version of the manuscript.

Funding: This work was supported by grants from the China Scholarship Council, the Swedish Medical Research Council, Neuroforbundet, Alltid Lite Sterkere, Hjärnfonden, Alzheimerfonden and Barncancerfonden.

Conflicts of Interest: The authors declare no conflict of interest.

\section{Abbreviations}

$\begin{array}{ll}\text { CNS } & \text { Central nervous system } \\ \text { DTR } & \text { Diphtheria toxin receptor } \\ \text { DTA } & \text { Diphtheria toxin subunit A }\end{array}$

\section{References}

1. Prinz, M.; Jung, S.; Priller, J. Microglia biology: One century of evolving concepts. Cell 2019, 179, 292-311. [CrossRef]

2. Salter, M.W.; Stevens, B. Microglia emerge as central players in brain disease. Nat. Med. 2017, 23, $1018-1027$. [CrossRef] [PubMed]

3. Han, J.; Harris, R.A.; Zhang, X.M. An updated assessment of microglia depletion: Current concepts and future directions. Mol. Brain 2017, 10, 25. [CrossRef]

4. Han, J.; Zhu, K.; Zhang, X.M.; Harris, R.A. Enforced microglial depletion and repopulation as a promising strategy for the treatment of neurological disorders. Glia 2019, 67, 217-231. [CrossRef]

5. Lund, H.; Pieber, M.; Harris, R.A. Lessons learned about neurodegeneration from microglia and monocyte depletion studies. Front. Aging Neurosci. 2017, 9, 234. [CrossRef]

6. Tsuji, S.; Di Martino, E.; Mukai, T.; Tsuji, S.; Murakami, T.; Harris, R.A.; Blomgren, K.; Aden, U. Aggravated brain injury after neonatal hypoxic ischemia in microglia-depleted mice. J. Neuroinflamm. 2020, 17, 111. [CrossRef]

7. Bruttger, J.; Karram, K.; Wortge, S.; Regen, T.; Marini, F.; Hoppmann, N.; Klein, M.; Blank, T.; Yona, S.; Wolf, Y.; et al. Genetic cell ablation reveals clusters of local self-renewing microglia in the mammalian central nervous system. Immunity 2015, 43, 92-106. [CrossRef]

8. Cronk, J.C.; Filiano, A.J.; Louveau, A.; Marin, I.; Marsh, R.; Ji, E.; Goldman, D.H.; Smirnov, I.; Geraci, N.; Acton, S.; et al. Peripherally derived macrophages can engraft the brain independent of irradiation and maintain an identity distinct from microglia. J. Exp. Med. 2018, 215, 1627-1647. [CrossRef]

9. Lund, H.; Pieber, M.; Parsa, R.; Han, J.; Grommisch, D.; Ewing, E.; Kular, L.; Needhamsen, M.; Espinosa, A.; Nilsson, E.; et al. Competitive repopulation of an empty microglial niche yields functionally distinct subsets of microglia-like cells. Nat. Commun. 2018, 9, 4845. [CrossRef]

10. Han, J.; Zhu, K.; Zhou, K.; Hakim, R.; Sankavaram, S.R.; Blomgren, K.; Lund, H.; Zhang, X.M.; Harris, R.A. Sex-specific effects of microglia-like cell engraftment during experimental autoimmune encephalomyelitis. Int. J. Mol. Sci. 2020, 21, 6824. [CrossRef]

11. Hirose, K.; Li, S.Z. The role of monocytes and macrophages in the dynamic permeability of the blood-perilymph barrier. Hear. Res. 2019, 374, 49-57. [CrossRef] [PubMed]

12. Zhang, L.Y.; Pan, J.; Mamtilahun, M.; Zhu, Y.; Wang, L.; Venkatesh, A.; Shi, R.; Tu, X.; Jin, K.; Wang, Y.; et al. Microglia exacerbate white matter injury via complement C3/C3ar pathway after hypoperfusion. Theranostics 2020, 10, 74-90. [CrossRef] [PubMed]

13. Willis, E.F.; MacDonald, K.P.A.; Nguyen, Q.H.; Garrido, A.L.; Gillespie, E.R.; Harley, S.B.R.; Bartlett, P.F.; Schroder, W.A.; Yates, A.G.; Anthony, D.C.; et al. Repopulating microglia promote brain repair in an IL-6-dependent manner. Cell 2020, 180, 833-846.e16. [CrossRef]

14. Beckmann, N.; Giorgetti, E.; Neuhaus, A.; Zurbruegg, S.; Accart, N.; Smith, P.; Perdoux, J.; Perrot, L.; Nash, M.; Desrayaud, S.; et al. Brain region-specific enhancement of remyelination and prevention of demyelination by the CSF1R kinase inhibitor BLZ945. Acta Neuropathol. Commun. 2018, 6, 9. [CrossRef] [PubMed] 
15. Du, X.; Xu, Y.; Chen, S.; Fang, M. Inhibited CSF1R alleviates ischemia injury via inhibition of microglia M1 polarization and NLRP3 pathway. Neural. Plast. 2020, 2020, 8825954. [CrossRef] [PubMed]

16. Gerber, Y.N.; Saint-Martin, G.P.; Bringuier, C.M.; Bartolami, S.; Goze-Bac, C.; Noristani, H.N.; Perrin, F.E. CSF1R inhibition reduces microglia proliferation, promotes tissue preservation and improves motor recovery after spinal cord injury. Front. Cell. Neurosci. 2018, 12, 368. [CrossRef]

17. Wesolowski, R.; Sharma, N.; Reebel, L.; Rodal, M.B.; Peck, A.; West, B.L.; Marimuthu, A.; Severson, P.; Karlin, D.A.; Dowlati, A.; et al. Phase Ib study of the combination of pexidartinib (PLX3397), a CSF-1R inhibitor, and paclitaxel in patients with advanced solid tumors. Ther. Adv. Med. Oncol. 2019, 11, 1758835919854238. [CrossRef]

18. Ma, D.; Zhao, Y.; Huang, L.; Xiao, Z.; Chen, B.; Shi, Y.; Shen, H.; Dai, J. A novel hydrogel-based treatment for complete transection spinal cord injury repair is driven by microglia/macrophages repopulation. Biomaterials 2020, 237, 119830. [CrossRef]

19. Elmore, M.R.P.; Hohsfield, L.A.; Kramar, E.A.; Soreq, L.; Lee, R.J.; Pham, S.T.; Najafi, A.R.; Spangenberg, E.E.; Wood, M.A.; West, B.L.; et al. Replacement of microglia in the aged brain reverses cognitive, synaptic, and neuronal deficits in mice. Aging Cell 2018, 17, e12832. [CrossRef]

20. Kraya, T.; Quandt, D.; Pfirrmann, T.; Kindermann, A.; Lampe, L.; Schroeter, M.L.; Kohlhase, J.; Stoevesandt, D.; Hoffmann, K.; Villavicencio-Lorini, P. Functional characterization of a novel CSF1R mutation causing hereditary diffuse leukoencephalopathy with spheroids. Mol. Genet. Genom. Med. 2019, 7, e00595. [CrossRef]

21. Groh, J.; Klein, D.; Berve, K.; West, B.L.; Martini, R. Targeting microglia attenuates neuroinflammation-related neural damage in mice carrying human PLP1 mutations. Glia 2019, 67, 277-290. [CrossRef] [PubMed]

22. Tanabe, S.; Saitoh, S.; Miyajima, H.; Itokazu, T.; Yamashita, T. Microglia suppress the secondary progression of autoimmune encephalomyelitis. Glia 2019, 67, 1694-1704. [CrossRef] [PubMed]

23. Kakae, M.; Tobori, S.; Morishima, M.; Nagayasu, K.; Shirakawa, H.; Kaneko, S. Depletion of microglia ameliorates white matter injury and cognitive impairment in a mouse chronic cerebral hypoperfusion model. Biochem. Biophys. Res. Commun. 2019, 514, 1040-1044. [CrossRef] [PubMed]

24. Vichaya, E.G.; Malik, S.; Sominsky, L.; Ford, B.G.; Spencer, S.J.; Dantzer, R. Microglia depletion fails to abrogate inflammation-induced sickness in mice and rats. J. Neuroinflamm. 2020, 17, 172. [CrossRef]

25. Warden, A.S.; Triplett, T.A.; Lyu, A.; Grantham, E.K.; Azzam, M.M.; DaCosta, A.; Mason, S.; Blednov, Y.A.; Ehrlich, L.I.R.; Mayfield, R.D.; et al. Microglia depletion and alcohol: Transcriptome and behavioral profiles. Addict. Biol. 2020, e12889. [CrossRef]

26. Lei, F.; Cui, N.; Zhou, C.; Chodosh, J.; Vavvas, D.G.; Paschalis, E.I. CSF1R inhibition by a small-molecule inhibitor is not microglia specific; affecting hematopoiesis and the function of macrophages. Proc. Natl. Acad. Sci. USA 2020, 117, 23336-23338. [CrossRef]

27. Ginhoux, F.; Greter, M.; Leboeuf, M.; Nandi, S.; See, P.; Gokhan, S.; Mehler, M.F.; Conway, S.J.; Ng, L.G.; Stanley, E.R.; et al. Fate mapping analysis reveals that adult microglia derive from primitive macrophages. Science 2010, 330, 841-845. [CrossRef]

28. Bennett, M.L.; Bennett, F.C.; Liddelow, S.A.; Ajami, B.; Zamanian, J.L.; Fernhoff, N.B.; Mulinyawe, S.B.; Bohlen, C.J.; Adil, A.; Tucker, A.; et al. New tools for studying microglia in the mouse and human CNS. Proc. Natl. Acad. Sci. USA 2016, 113, E1738-E1746. [CrossRef]

29. Sjostedt, E.; Zhong, W.; Fagerberg, L.; Karlsson, M.; Mitsios, N.; Adori, C.; Oksvold, P.; Edfors, F.; Limiszewska, A.; Hikmet, F.; et al. An atlas of the protein-coding genes in the human, pig, and mouse brain. Science 2020, 367, 6482. [CrossRef]

30. Wollberg, A.R.; Ericsson-Dahlstrand, A.; Jureus, A.; Ekerot, P.; Simon, S.; Nilsson, M.; Wiklund, S.J.; Berg, A.L.; Ferm, M.; Sunnemark, D.; et al. Pharmacological inhibition of the chemokine receptor CX3CR1 attenuates disease in a chronic-relapsing rat model for multiple sclerosis. Proc. Natl. Acad. Sci. USA 2014, 111, 5409-5414. [CrossRef]

31. Merry, T.L.; Brooks, A.E.S.; Masson, S.W.; Adams, S.E.; Jaiswal, J.K.; Jamieson, S.M.F.; Shepherd, P.R. The CSF1 receptor inhibitor pexidartinib (PLX3397) reduces tissue macrophage levels without affecting glucose homeostasis in mice. Int. J. Obes. 2020, 44, 245-253. [CrossRef] [PubMed] 
32. Shi, Y.; Manis, M.; Long, J.; Wang, K.; Sullivan, P.M.; Remolina Serrano, J.; Hoyle, R.; Holtzman, D.M. Microglia drive APOE-dependent neurodegeneration in a tauopathy mouse model. J. Exp. Med. 2019, 216, 2546-2561. [CrossRef] [PubMed]

33. Butowski, N.; Colman, H.; De Groot, J.F.; Omuro, A.M.; Nayak, L.; Wen, P.Y.; Cloughesy, T.F.; Marimuthu, A.; Haidar, S.; Perry, A.; et al. Orally administered colony stimulating factor 1 receptor inhibitor PLX3397 in recurrent glioblastoma: An ivy foundation early phase clinical trials consortium phase II study. Neuro. Oncol. 2016, 18, 557-564. [CrossRef] [PubMed]

Publisher's Note: MDPI stays neutral with regard to jurisdictional claims in published maps and institutional affiliations.

(C) 2020 by the authors. Licensee MDPI, Basel, Switzerland. This article is an open access article distributed under the terms and conditions of the Creative Commons Attribution (CC BY) license (http://creativecommons.org/licenses/by/4.0/). 